\title{
Characteristic patients with oral mucositis receiving 5-FU chemotherapy at Hasan Sadikin Hospital Bandung
}

\author{
Syarifah Fatimah*, Irna Sufiawati*, Indra Wijaya** \\ *Department of Oral Medicine Faculty of Dentistry Universitas Padjadjaran Indonesia \\ **Department of Hematology Oncology Internal Medicine Faculty of Medicine Universitas \\ Padjadjaran Indonesia
}

\begin{abstract}
Introduction: Oral mucositis is an inflammatory reaction of oral mucous membrane that often appears in cancer patients due to the chemotherapeutic agents, such as 5-fluorouracil (5-FU). The aim of this study was to describe the characteristic patients who receive 5-FU and had oral mucositis. Methods: This study was conducted on 41 patients with cancer receiving 5-FU chemotherapy at Dr. Hasan Sadikin Hospital Bandung. The data was retrieved through interviews to find out patient's characteristic; nutritional status examination by using body mass index measurement; and oral examination. Severity level was determined by using National Cancer Institute's Common Toxicity Criteria scale, and the level of pain was measured by Numeric Pain Intensity Rating scale. Results: This research have shown $60.98 \%$ patient with cancer had received 5-FU chemotherapy treatment, and $44 \%$ with poor nutritional status (underweight). Oral mucositis was only found at non-keratinized mucous. The finding of this study was patients that receiving 5 -FU chemotherapy treatment diagnosed with oral mucositis was on the 1 st stadium (52\%) and the 2 nd stadium (44\%) with the level of pain was on the mild level (48\%) and moderate level (32\%). Conclusion: Oral mucositis was found on patients with cancer that received 5-FU chemotherapy with a variety of characteristics, nutritional statuses, locations, levels of severity and pain.
\end{abstract}

Keywords: Cancer, 5-FU Chemotherapy agents, oral mucositis.

\section{INTRODUCTION}

Cancer is an uncontrolled cell's growth in particular body parts. It began with a sequence of genetical changes that lead to apoptosis resistance; then the abnormal cells become immortal. Various external factor that lead to cancer such as cigarettes, an infectious organism, poor diet and also internal factors such as inherited genetic mutation, hormonal changes, and immune condition. All of that factor altogether or as a sequence on to another known as the cause of cancer. ${ }^{1,2}$

Cancer is known as one of the main cause of deaths all over the world. In 2012, there were 14 million new cases and lead to 8,2 million deaths worldwide. Lung, liver, abdominal, colorectal, and breast cancer were being the most of the cancer types that contribute to deaths annually. In 2016, approximately 1.685.210 new cases had been diagnosed in the United States, and 595.690

Corresponding author: Irna Sufiawati, Department of Oral Medicine Faculty of Dentistry Universitas Padjadjaran Indonesia Jl. Sekeloa Selatan No. 1 Bandung, West Java-Indonesia, Phone/Fax: +6222-2504985, Email:irna.sufiawati@fkg.unpad.ac.id 
patients would have die because of the illness. More than $60 \%$ of new cases on cancer in the world, have been found in Africa, Asia, Central and South America; at these areas, the finding reveals $70 \%$ of deaths were caused by cancer.

In Indonesia, the prevalence on a national level in 2013, cancer patients among all ages was approximately $1.4 \% \quad(347,792$ patients $)$. Yogyakarta province has the highest number of prevalence, which is around $4.1 \%$. The mortality rate is higher on male compared to female (207.9 deaths on every 100.000 male, and 145.4 deaths on every 100.000 female patients with cancer). Commonly cancer is developed in older people, $78 \%$ of patient that had diagnosed with cancer was on or above 55 years old. ${ }^{3}$ One of the therapies given to cancer patients is chemotherapy. Chemotherapy is the treatment of cancer with the use of anti-cancer medicines with the principle of killing cancer cells that are growing rapidly. Agent 5-fluorouracil (5-FU) is a widely used anticancer drug for the treatment of various cancers such as breast, colorectal cancer, and head and neck. Agent 5-FU can also kill normal cells of the body, thus lead to a variety of negative effects on the body. Effect of Agent 5-FU in the oral cavity that is the most common one is the oral mucositis. ${ }^{4,5}$

Oral mucositis is an inflammatory reaction of the mucous membranes of the mouth due to chemotherapeutic agents. Thirty to fifty percent oral mucositis occurred in oral cavity due to chemotherapy with 5-FU for treatment of solid cancers and lymphoma. Oral mucositis's symptoms usually such as pain, ulceration, bleeding, xerostomia, and odynophagia. The severity of oral mucositis can be assessed by a variety of classification systems, one of which is, according to the National Cancer Institute $(\mathrm{NCl})$. The severity of the mucositis according to $\mathrm{NCl}$ is divided in 5 scales, where the scale of 0 interpreted as absence of the presence of oral mucositis, and 4 is a scale with the highest level of severity. ${ }^{1,6}$

The symptoms of pain and ulceration in the mouth cavity due to oral mucositis can cause discomfort in the mouth, inability to tolerate food or fluid until it finally decreased nutritional status and influenced the life of the patient. Decreased nutrients may inhibit many of the physiological systems and reduce the quality of life of patients and their performance status. Patients with poor performance status will have a poor prognosis also from cancer or any other diseases that suffered. Oral hygiene maintenance is one of the ways to reduce the prevalence of the occurrence of complications of oral mucositis in chemotherapy treatment. ${ }^{7,8}$

Complications of oral mucositis can lead to oral function so that it can increase morbidity of the patients. Also the oral mucositis can lead to the development of serious complications such as infection of the oral, which can degrade the quality of life of cancer patients, which increases the mortality. ${ }^{9}$ Currently, there was no data regarding the description of the occurrence of oral mucositis in cancer patients that received chemotherapy-based 5-FU in Dr. Hasan Sadikin hospital. Therefore, this studi aimed to find out the charateristics of patients with oral mucositis in cancer patients that received chemotherapybased 5-FU in Dr. Hasan Sadikin hospital in Bandung, which was the largest referral hospital in West Java Province that has a potential of information, and a fairly complete data.

\section{METHODS}

The type of research that was conducted in this study was a descriptive research. The population of this research are cancer survivors who got 5-FU-based chemotherapy in outpatient services of the Hematology division, Oncology Department of Internal Medicine at Dr. Hasan Sadikin Hospital Bandung. Research samples of 41 patients were taken using the method of sampling, i.e. consecutive sampling based on predetermined criteria based on both inclusion and exclusion criteria. ${ }^{10}$

The data was retrieved through interviews to find out patient's characteristic; nutritional status examination measured and recorded by using body mass index measurement; and oral examination was done to get intra oral conditions. Severity level was determined by using National Cancer Institute's Common Toxicity Criteria scale, and the level of pain was measured by Numeric Pain Intensity Rating scale.

\section{RESULTS}

The data obtained from the results of the examination and interview on 42 patients with 
Tabel 1. Characteristic distribution of patients with oral mucositis based on sex and age

\begin{tabular}{lll}
\hline Category & Total & Percentage (\%) \\
\hline Sex & & \\
Male & 11 & 44 \\
Female & 14 & 56 \\
Total & 25 & 100 \\
Age (year) & & \\
$18-25$ & 0 & 0 \\
$26-35$ & 3 & 12.00 \\
$36-45$ & 9 & 32.00 \\
$46-55$ & 10 & 40.00 \\
$56-65$ & 4 & 16.00 \\
$>66$ & 0 & 0 \\
\hline Total & 25 & 100.00 \\
\hline
\end{tabular}

Tabel 2. Oral mucositis severity level distribution according to $\mathrm{NCl}$

\begin{tabular}{lll}
\hline Stadium & Patients (people) & Percentage (\%) \\
\hline 1 & 13 & 52.00 \\
2 & 11 & 44.00 \\
3 & 0 & 0 \\
4 & 1 & 4,00 \\
\hline Total & 25 & 100.00 \\
\hline
\end{tabular}

Tabel 3. Oral mucositis characteristic distribution based on nutrional status

\begin{tabular}{lll}
\hline Nutrional status & Total & Percentage (\%) \\
\hline Very skinny & 4 & 16.00 \\
Skinny & 11 & 44.00 \\
Normal & 10 & 40.00 \\
Overweight & 0 & 0 \\
Obesity & 0 & 0 \\
\hline Total & 25 & 100.00 \\
\hline
\end{tabular}

Tabel 4. Oral mucositis distribution based on level of pain, according to numeric pain rating scale.

\begin{tabular}{lll}
\hline Pain index & Total & Percentage (\%) \\
\hline No pain & 4 & 16.00 \\
Mild pain & 12 & 48.00 \\
Moderate pain & 8 & 32.00 \\
Severe pain & 1 & 4.00 \\
\hline Total & 25 & 100.00 \\
\hline
\end{tabular}

cancer, based on sex (Table 1) and age (Table 2 ), the prevalence of mucositis oral in cancer patients who received 5-FU-based chemotherapy in Dr. Hasan Sadikin Bandung hospital was on high category $(60.98 \%)$. According to $\mathrm{NCl}$, the oral mucositis was most often found at the stadium 1 $(52 \%)$ and $2(44 \%)$ with the degree of the perceived pain sufferers in the form of a mild degree of pain (48\%) and moderate (32\%). Besides, oral mucositis characteristic distribution based on nutrional status can also be seen at Table 3, mostly skinny (44\%) and normal state (40\%).

Oral mucositis distribution based on level of pain, according to numeric pain rating scale were seen at table 4 , there were mostly mild pain $(48 \%)$ and moderate pain (32\%).

Cancer's patients with oral mucositis that received 5-FU-based chemotherapy treatment tend to be higher on female $(56 \%)$ with age range $46-55$ years $(40 \%)$, and nutritional status was underweight (44\%). The location of the oral mucositis in the oral cavity was found in entirely non-keratinized mucous.

\section{DISCUSSION}

Cancer patients that undertaken chemotherapybased 5-FU were 41 people, which consist of 15 male and 26 . Based on the previous studies, cancer patients who got 5-FU-based chemotherapy more often found at the age of 46 to 55 years $(41.46 \%)$ as well as at the age of 36 to 45 years (36.58\%). The overall incidence of cancer is more common in the ranges of age 40 years and over but varies depending on the type of cancer. 11

The type of cancer that is discovered in the study is entirely solid cancer carcinoma types. 5-fluorouracil (5-FU) agent-based as chemotherapy treatment is an indication for carcinoma especially colorectal cancer, breast, stomach, head and neck. Considering the type of cancer, breast cancer most often occurred in female patients, and that is as much as 15 people $(36.58 \%)$ while the nasopharynx cancer sufferers have some male $(24.39 \%)$ more than female $(12.19 \%)$. Colorectal cancer was found in the study have a similar number of sufferers of the same lot on male and female, that is as much as five people (12.19\%). The data are shown from the National Cancer Institute the year 2015 asserting that breast cancer the most frequently cancer type experienced by female and cancer of the nasopharynx is more prevalent in male than 
female by comparison 2:1.12,13 Cancer patients who were undergo 5-FU-based chemotherapy experienced oral mucositis $(60.98 \%)$ more than those patients without 5-FU-based chemotherapy treatment $(39.02 \%)$. This data is by previous research suggesting that the prevalence of oral mucositis $30-60 \%$ occur in people with cancer who got 5-FU-based chemotherapy.6 Based on gender differences, the oral mucositis was much more occurred on as many as 14 women (56\%) and men as many as 11 people (44\%).

Research results in accordance with previous research suggesting that oral mucositis are more likely to occur in the female sex than men. ${ }^{8}$ Based on age groups, oral mucositis was mostly found at the age of 46 to 55 years a total of 10 people $(40 \%)$ and at the age of 36 to 45 years as many as 8 people (32\%). This research data in accordance with other studies suggesting that cancer patients above 40 years old solid treated with 5 -FU have higher risk exposed to oral mucositis. ${ }^{14}$

Oral mucositis often found in patients with underweight nutritional status, i.e. a total of 11 people $(44 \%)$ followed the normal nutritional status of as many as ten people (40\%). These results are in accordance with the literature that shows low body mass index is one of the risk factors for the emergence of oral mucositis. Also, the perceived pain sufferers due to oral mucositis can reduce oral intake and caused a decrease in nutritional status of the patients. From the results of the research appear that some patients are still in the normal category of their nutritional status due to the average degree of perceived pain, which is considered as in the mild category level of pain severity, therefore, no food intake disturbance through the oral route. ${ }^{8,15}$

The location of oral mucositis in the oral cavity was as many as 25 people (100\%) on nonkeratinized mucous, in contrary, none of it to be found at the keratinized mucous area. The results of this study by the literature that concluded the oral mucositis occurs only at non-keratinized mucous such as the lateral and ventral tongue, buccal, labial, mouth and soft palate mucosa. ${ }^{16}$

The most frequently severity degree level was found on the first stadium of cancer by as much as 13 people (52\%) followed by the 2 nd stadium as much of 11 people $(44 \%)$ and fourth stadium as much as one person (4\%). There was no third stadium of cancer was found with the oral mucositis. This research data by previous research suggesting that mild to moderate mucositis i.e. stadium 1 and two according to $\mathrm{NCl}$ common more than $40 \%$ on the chemo treatments that use agent 5-FU compared to other regimens. ${ }^{17,18}$

Level of perceived pain sufferers with oral mucositis average is a mild pain as many as 12 people (48\%) and pain was as much as eight people $(32 \%)$. Severe pain found in one person the sufferer $(4 \%)$. The literature notes that the subjective symptoms of oral mucositis are there an extensive pain due to the changes in the components of mucous cells ${ }^{18.19}$. In addition, other research describes that the pain is mild to moderate the perceived consequences of oral mucositis sufferers correspond to the degree of severity experienced, i.e. the first and second stage stadium according to the $\mathrm{NCl}$. Pain can also affect the nutritional status of sufferers because of the oral intake disturbances.

\section{CONCLUSION}

Oral mucositis was found on patients with cancer that received 5-FU chemotherapy with a variety of characteristics, nutritional statuses, locations, levels of severity and pain.

\section{REFERENCES}

1. Davies AN, Joel BE. Oral complications of cancer and it's management. New York: Oxford University Press; 2010. p. 123-9.

2. American Cancer Society. Cancer 2015. Available from: http://www.cancer.org

3. National Cancer Institute. Data statistics of cancer. 2015. Available at http: / / www.cancer. gov

4. Greenberg MS, Michael G, Jonathan AS. Burket's oral medicine diagnosis and treatment. $11^{\text {th }}$ ed. Ontario: B.C Decker Inc.; 2008. p. 385-411.

5. Airley R. Cancer chemotherapy: basic science to the clinic. West Sussex: Wiley-Blackwell; 2009. p. 55-9.

6. Lopez BC, Carmen GE, Gracia SP. Dental treatment considerations in the chemotherapy patient. J Clin Exp Dent 2011:3(1):e31-42.

7. Broadfield L, Hamilton J. Best practice 
guidelines for the management of oral complications from cancer therapy. Canada: Crown; 2006. p. 15-22.

8. Yarbro $\mathrm{CH}$, Debra W, Barbara HG. Cancer nursing: principles and practice. $7^{\text {th }}$ ed. Massachusetts: Jones and Bartlett Publishers; 2011. p. 458-87.

9. Davies A, Ilora F. Oral care in advanced disease. New York: Oxford University Press; 2005. p. 171-85.

10. Budiarto E. Metodologi penelitian kedokteran: sebuah pengantar. Jakarta: EGC; 2004. p. 2855.

11. Mohan H. Essential pathology for dental students. India: Jaypee; 2005. p. 229-79.

12. Kirkwood JM, Lotze MT, Yasko JM. Current cancer therapeutics. $2^{\text {nd }}$ ed. London: Churchill Livingstone; 1997. p. 50-9.

13. Cooper JS, Lu JJ, Lee AWM. Nasopharyngeal cancer: multidisciplinary management. New
York: Springer; 2010.

14. Holland JF, Frei E, Kufe DW, et al. Cancer medicine. $8^{\text {th }}$ ed. USA: People's Medical Publishing House; p: 1885-900.

15. Kintzel PE. Management of oral mucositis in cancer patients. Michigan: Mc. Mahon Publ; 2011. p. 1-6

16. Olver I. The MASCC textbook of cancer supportive care and survivorship. New York: Springer; 2011

17. Lionel D, Christophe L, Marc A, Jean-Luc, C. Oral mucositis induced by anticancer treatments: physiopathology and treatments. Ther Clin Risk Manag 2006Jun;2(2):159-168

18. Clark GT, Dionne RA. Orofacial pain: a guide to medications and management. Oxford: John Wiley \& Sons Inc.; 2012.

19. Perry MC. The chemotherapy source book. $4^{\text {th }}$ ed. Philadelphia: Lippincott Williams and Wilkins; 2008. 